\title{
Antitussives and substance abuse
}

This article was published in the following Dove Press journal:

Substance Abuse and Rehabilitation

5 November 2013

Number of times this article has been viewed

\section{Jarrett M Burns}

Edward W Boyer

Division of Medical Toxicology, Department of Emergency Medicine, University of Massachusetts Medical School, Worcester, MA, USA
Correspondence: Edward W Boyer Division of Medical Toxicology, Department of Emergency Medicine, University of Massachusetts Medical School, 55 Lake Avenue North, Worcester, MA 0I655, USA

Tel + I 508 42I 1400

Email edward.boyer@childrens.harvard. edu
Abstract: Abuse of antitussive preparations is a continuing problem in the United States and throughout the world. Illicit, exploratory, or recreational use of dextromethorphan and codeine/ promethazine cough syrups is widely described. This review describes the pharmacology, clinical effects, and management of toxicity from commonly abused antitussive formulations.

Keywords: dextromethorphan, purple drank, sizzurp, codeine/promethazine

\section{Introduction}

An article published in The Lancet in May 2007 highlighted a major growing health problem in the United States: abuse of pharmaceutical drugs. Experts ascribe the rise in the abuse of prescription drugs to the increased availability of these drugs, growing social acceptance of sedatives, painkillers, and anti-anxiety medications; and the perception, especially among young people, that pharmaceutical drugs are safe. ${ }^{1}$

Abuse of over the counter (OTC) antitussive preparations is a continuing problem in the United States and throughout the world. In 2008, the Substance Abuse and Mental Health Services Administration released the Annual National Survey on Drug Use and Health report, which revealed that in 2006 around 3.1 million people in the United States aged 12-25 stated that they had used OTC cough and cold medicine to "get high."2

Since the early 1990s, there have been numerous reports of codeine cough syrup abuse from India, Japan, People's Republic of China, and the United States. ${ }^{3-7}$ In addition, dextromethorphan misuse and abuse among children and adolescents has been well documented for decades. ${ }^{8,9}$ According to the 2011 report by the American Association of Poison Control Centers (AAPCC) National Poison Data System, which monitors the average annual prevalence of dextromethorphan abuse, there seems to be a plateau that has occurred since $2006 .{ }^{10}$ The explanation is likely multifactorial and based upon a combination of legislative, educational, and economic initiatives. ${ }^{11}$ Perhaps there has been a shift to abuse of other more popular, readily available, and easily attainable cough and cold preparations, such as those containing codeine.

Since the late 1990s, abuse of codeine promethazine hydrochloride cough syrup (CPHCS) has become a growing public health problem, particularly in the southern United States. ${ }^{12}$ Known by the street names "lean", “drank", "barre", "purple stuff”, "syrup", and "sizzurp", abuse of CPHCS has become more popular since the late Houston-native rap artist/producer DJ Screw created a genre of music, aptly called "screw music," inspired by intoxication on codeine and promethazine. ${ }^{13}$ Recently, many star athletes and celebrities have been profiled by the national media as a result 
of their association with, and abuse of, CPHCS. Former National Football League quarterback Jamarcus Russell was arrested in 2010 for possession of large amounts of codeine without a prescription. ${ }^{13}$ In March 2013, famous hip-hop rapper Lil Wayne spent several days in an intensive care unit at a Los Angeles hospital after suffering seizures as a result of "sizzurp" overdose and intoxication. ${ }^{14}$ Interestingly, DJ Screw died in November 2000 of an apparent multi-substance overdose including codeine which came from prescriptionstrength cough syrup. ${ }^{15}$

Despite media attention and the well documented dangers of cough syrup abuse for years, including a recent 2011 study by Hou et al, which associated chronic codeine cough syrup abuse to alterations in the dopaminergic system and serious brain damage, abuse of these preparations remains rampant. ${ }^{16}$ The 29th Annual Report of the AAPCC National Poison Data System published in December 2012, documents 74,995 exposures to cold and cough preparations. This accounts for $2.73 \%$ of all exposures called into United States poison centers and ranks "cold and cough preparations" number eleven on the list of top 25 substance categories most frequently involved in human exposures. Over 9,400 (12.5\%) of the exposures to cough and cold preparations were the result of intentional abuse or misuse. ${ }^{17}$

\section{Pharmacology and abuse potential of antitussives}

Antitussives elicit their clinical affect by directly inhibiting the medullary cough center of the brain. ${ }^{18}$ Codeine and dextromethorphan are two opioid agents with cough suppressant activity. Various models suggest that cough suppression occurs via agonism of the $\mu_{2}$ or $\kappa$ opioid receptors, or antagonism of the $\delta$ opioid receptor. The $\sigma$ or N-methyl-daspartate (NMDA) receptors are likely also involved. ${ }^{19-21}$

\section{Dextromethorphan}

Dextromethorphan is a dissociative agent, similar to ketamine and phencyclidine. Dextromethorphan contains an alkylated amine adjacent to a cyclohexane ring; a structural moiety common to the dissociative agents. ${ }^{8}$ Dextromethorphan has equal antitussive effects as codeine but does not possess analgesic or addictive properties. ${ }^{22}$

Dextromethorphan reaches maximum serum concentrations in 2.5 hours after ingestion. ${ }^{23}$ The major metabolite of dextromethorphan, dextrorphan, achieves peak plasma concentrations at 1.6 to 1.7 hours following ingestion. ${ }^{24}$ The volume of distribution of dextromethorphan in humans is thought to be $5.0-6.7 \mathrm{~L} / \mathrm{kg} .{ }^{25}$ Dextromethorphan and its metabolites undergo renal elimination, with less than $0.1 \%$ of the drug being eliminated in the feces. ${ }^{25}$ The half-life of the parent compound is approximately $2-4$ hours in individuals with normal metabolism. ${ }^{8}$

Dextromethorphan is metabolized by cytochrome CYP2D6. In humans, CYP2D6 is a genetically polymorphic enzyme responsible for metabolizing numerous substances. ${ }^{26}$ Rapid metabolizers (those individuals with extensive CYP2D6 activity and, hence, increased rates of dextromethorphan metabolism) constitute about $85 \%$ of the United States population and are more likely to abuse dextromethorphan because they get a quicker, more intense high. Dextromethorphan undergoes 3-demethylation to dextrorphan and, to a lesser extent, N-demethylation to 3-methoxymorphinan. ${ }^{24,26}$ Both of these metabolites are further demethylated to 3-hydroxymorphinan. Dextrorphan is the active metabolite that produces neurobehavioral effects, while dextromethorphan does not exhibit the same actions. Dextromethorphan is therefore a prodrug, and the metabolic conversion of dextromethorphan to dextrorphan is an important determinant of the abuse potential of dextromethorphan in an individual. Experienced dextromethorphan users describe tachyphylaxis to the drug, but whether this effect is from alterations in cytochrome function or other effects is not known. ${ }^{8}$

In therapeutic dosing, dextrorphan binds with high affinity to $\sigma$-receptors to produce its antitussive activity without exhibiting classic opiate effects that occur from binding into $\mu$ and $\delta$ opiate receptors. In larger doses, dextrorphan, like phencyclidine and ketamine, antagonizes NMDA receptors by binding to the $\mathrm{Ca}^{2+}$ cation channel. Blockage of NMDA receptors modulates excitatory neurotransmission, the end result of which is the production of specific neurobehavioral findings such as dissociative, "out-of-body" experiences. Dissociative agents also demonstrate adrenergic effects including hypertension, tachycardia, and diaphoresis by inhibiting peripheral and central catecholamine uptake. ${ }^{27,28}$ Dextromethorphan also exhibits binding activity at serotonergic receptors, which may contribute to its abuse potential. ${ }^{29}$

\section{CPHCS}

The street cocktail "purple drank" is a concoction that can take several forms. Most involve some type of cough syrup containing the opiate agonist codeine and promethazine hydrochloride, an antihistamine with sedative properties. The cough syrup is typically mixed with a soft drink and candy, with some variants including alcohol. ${ }^{13}$

Codeine, or 3-methylmorphine, is a natural isomer of methylated morphine. It is a phenanthrenic alkaloid 
with three fused benzene rings at its backbone. ${ }^{30}$ Codeine is the second-most predominant alkaloid in opium, with concentrations approaching 3\%. Although codeine can be extracted from natural sources, a semi-synthetic process via methylation of morphine is the primary source of codeine for pharmaceutical use. ${ }^{31}$

Oral absorption of codeine from the gastrointestinal tract is almost complete $(94 \% \pm 4 \%)$. Onset of action occurs 30-45 minutes after administration, when given orally. ${ }^{31}$ Peak effect is reached within 1-2 hours, and the duration of antitussive action is $4-6$ hours. ${ }^{31}$ Volume of distribution is found to be $3.6 \mathrm{~L} / \mathrm{kg}$, indicating extensive distribution of the drug into tissues. Plasma protein binding is low at $7 \%-25 \%$. Pre-systemic metabolism is noted to be $50 \%$, and metabolism is reported to be hepatic. Renal excretion accounts for the major elimination pathway, and the plasma half-life is 3 hours. Most of the excretion products appear in the urine within 6 hours, and $40 \%-60 \%$ of the codeine is excreted free or conjugated, approximately $5 \%-15 \%$ as free and conjugated morphine and $10 \%-20 \%$ as free and conjugated norcodeine. ${ }^{31-33}$

Metabolism of codeine follows three major pathways: conjugation to codeine-6-glucuronide, N-demethylation to norcodeine, and O-demethylation to morphine (Figure 1). The conjugation pathway is quantitatively the most important, with codeine-6-glucuronide recovered in urine accounting for $70 \%$ of an oral dose of codeine. The corresponding values for $\mathrm{N}$-demethylation and O-demethylation are probably $7 \%$ and $5 \%$, respectively; approximately $4 \%$ is excreted unchanged. ${ }^{19}$

Codeine, similar to dextromethorphan, is a prodrug and inactive opioid agonist, requiring metabolic activation by O-demethylation to morphine by CYP2D6. This typically represents a minor metabolite pathway for codeine metabolism. N-demethylation into norcodeine by CYP3A4 and glucuronidation are more prevalent but produce inactive metabolites. The need for conversion to morphine explains why approximately $5 \%-7 \%$ of White patients, who are devoid of CYP2D6 function, cannot derive an analgesic response from codeine. Rarely, ultra-rapid CYP2D6 metabolizers produce an unexpectedly large amount of morphine, with resulting life-threatening opioid toxicity. ${ }^{19}$

Promethazine hydrochloride is a phenothiazine derivative that acts primarily as a histamine (H1) receptor antagonist, with moderate muscarinic dopamine (D2)-receptor-

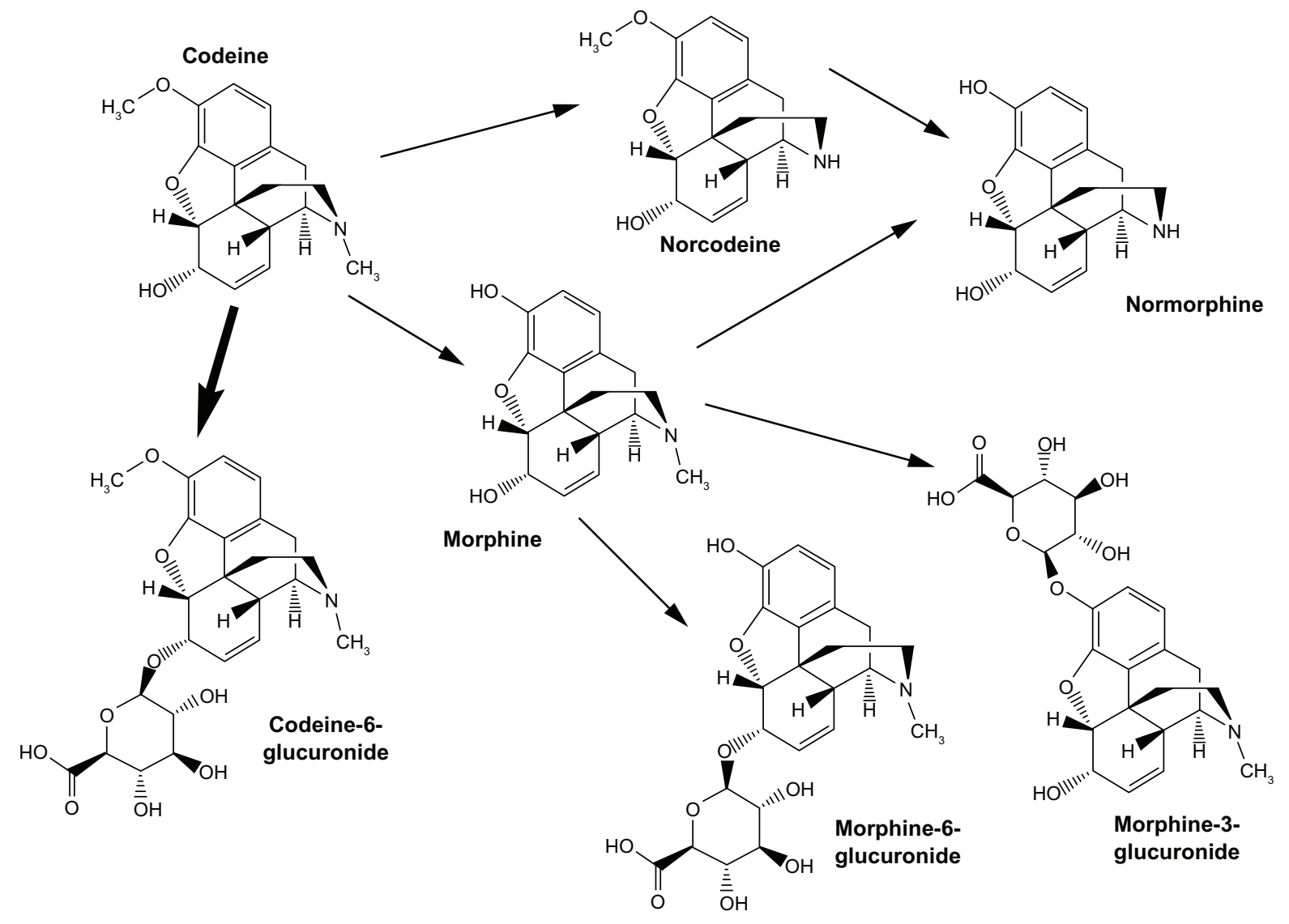

Figure I Metabolism pathways of codeine. 
blocking effects (Figure 2). It is used in cough syrups for its antihistaminic, antiemetic, and sedative effects. ${ }^{34}$

Promethazine hydrochloride is well absorbed from the gastrointestinal tract, with an average of $88 \%$ of the dose absorbed after oral administration. However, the absolute bioavailability is only $25 \%$ because of first-pass clearance. Clinical effects are apparent within 20 minutes after oral, rectal, or intramuscular administration, and the effects last 4-6 hours. Volume of distribution is found to be $13.4 \mathrm{~L} / \mathrm{kg}$, and plasma protein binding is 76\%-93\%. Promethazine undergoes extensive hepatic metabolism to a variety of metabolites. The sulfoxides of promethazine and N-demethylpro-methazine are the predominant metabolites and are excreted in the urine. Negligible amounts of unchanged drug are recovered in the urine. The plasma half-life is approximately 7-14 hours. ${ }^{34,35}$

Codeine is known to be subject to abuse for those in search of the subjective effects of euphoria, elation, analgesia, and "liking." It has been postulated that O-demethylation metabolite agonism at $\mu$ receptors contributes substantially to the abuse liability of codeine. Pretreatment with selective, potent CYP2D6 inhibitors like quinidine can produce a durationdependent inhibition of O-demethylation of codeine and a decrease in the positive subjective effects of codeine. ${ }^{36}$

Euphoria from promethazine is very rare, except with high intravenous doses and/or co-administration with opioids and other central nervous system depressants (alcohol). ${ }^{32}$ The concern here of course is that "sizzurp" and other street concoctions contain exactly that: promethazine, codeine, and alcohol, along with other potential sedatives. Consuming large quantities of these drugs prolongs and intensifies each drug's sedative effects and is responsible for an increase in life-threatening events. ${ }^{3,12}$

\section{Clinical effects and toxicity Dextromethorphan}

The dose of ingested dextromethorphan determines the neurobehavioral outcome. Recreational users of dextromethorphan

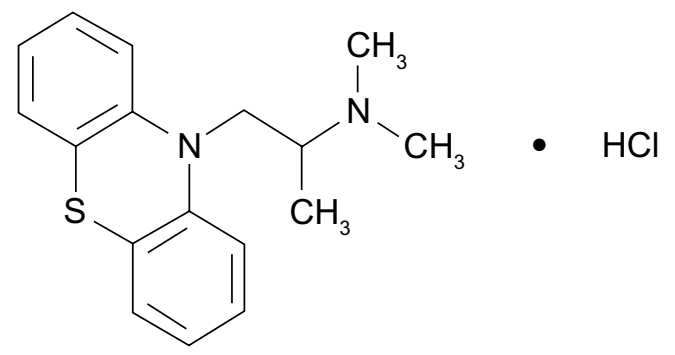

Figure 2 Promethazine hydrochloride structure. describe several intensities of effect from the drug, known as "plateaus." ${ }^{37}$ The first plateau is a mild stimulant effect similar to that of methylenedioxymethamphetamine. The second plateau is described as similar to a combination of concurrent ethanol and marijuana intoxication, although some users describe hallucinations as occurring at this stage. ${ }^{38}$ The third level is a dissociative, "out-of body" state, like that produced by a low recreational dose of ketamine, and the fourth plateau is a fully dissociative condition similar to that produced by ketamine intoxication. ${ }^{37}$ Neurobehavioral effects begin within 30-60 minutes of ingestion and persist for approximately 6 hours.

To produce nominal effects from dextromethorphan - the first plateau - online drug encyclopedias such as Erowid (http://www.erowid.org) describe a dose of between 100 and $200 \mathrm{mg}$. The second plateau may be achieved with between 200 and $400 \mathrm{mg}$, while the third plateau can be achieved with between 300 and $600 \mathrm{mg}$ of the drug. An ingested dose of 600-1,500 mg dextromethorphan may produce a full-blown dissociative state. These doses depend upon several factors, such as an individual's CYP2D6 subtype and bodyweight, as well as the degree of tolerance to dextromethorphan. ${ }^{37}$

The clinical presentation of dextromethorphan intoxication therefore depends on the ingested dose. Minimally intoxicated persons may develop tachycardia, hypertension, vomiting, mydriasis, diaphoresis, nystagmus, euphoria, loss of motor coordination, and giggling or laughing. ${ }^{37}$ In addition to the above findings, persons with moderate intoxication may demonstrate hallucinations and a distinctive, plodding ataxic gait that has been compared with "zombie-like" walking. ${ }^{38}$ Severely intoxicated individuals in a dissociated state may be agitated or somnolent. ${ }^{28,37,39,40}$ Extremely agitated patients may develop hyperthermia and metabolic acidosis. ${ }^{8}$

Experienced dextromethorphan users describe a rapidly developing and persistent tolerance to the drug. ${ }^{37}$ Dependence on dextromethorphan is rarely described. ${ }^{41-43}$ Although dextromethorphan is not thought to have addictive properties, susceptible individuals may develop craving and habitual use of the drug. ${ }^{39,44}$ An abstinence syndrome may be associated with cessation of dextromethorphan abuse that is characterized by dysphoria and intense cravings. ${ }^{41,43,45,46}$ Toxic psychosis and cognitive deterioration may arise from chronic use of the drug. ${ }^{41,45,46}$

Toxicity in the setting of dextromethorphan abuse can arise from additional sources. OTC cough formulations frequently contain, in addition to dextromethorphan, other pharmaceutical agents such as chlorpheniramine, acetaminophen, or pseudoephedrine ${ }^{47}$ Chlorpheniramine is an 
H1-receptor antagonist. Consequently, individuals who have abused chlorpheniramine-containing dextromethorphan formulations may also exhibit anticholinergic signs and symptoms (eg, tachycardia; warm, dry, flushed skin; dry mucosa; mydriasis; agitated delirium; urinary retention; and gastrointestinal dysmotility). Severe chlorpheniramine intoxication has also been associated with seizure activity, rhabdomyolysis, and hyperthermia. ${ }^{40}$ Pseudoephedrine intoxication may mimic that of chlorpheniramine, except that patients may exhibit diaphoresis. In contrast, overdose of acetaminophen, an antipyretic and analgesic that is a component of over 100 cough and cold preparations, produces delayed hepatic injury and, potentially, death. Lastly, because dextromethorphan is produced as the crystalline hydrobromide salt, bromism is a rare consequence that has been identified in heavy chronic abusers of dextromethorphan. ${ }^{48}$ Bromism is caused by a neurotoxic effect on the brain, which results in somnolence, psychosis, seizures, and delirium. ${ }^{49}$

Drug interactions exist between dextromethorphan and other substances, the best characterized of which is serotonin syndrome. This condition typically occurs from the interaction between dextromethorphan and selective serotonin reuptake inhibitors or monoamine oxidase inhibitors, but concurrent administration of antibiotics (eg, linezolide), opiate analgesics (eg, meperidine and tramadol), or drugs of abuse (eg, Syrian rue) could precipitate the condition. ${ }^{50}$ Patients with serotonin syndrome may demonstrate the clinical triad of mental status changes, autonomic instability, and muscular hypertonicity. ${ }^{51}$

\section{CPHCS}

It is difficult to determine what constitutes a standard toxic or lethal dose of codeine. However, the lethal oral dose of codeine in an average adult is reported to be in the range of 500-1,000 mg. One case reported a human death at $12 \mathrm{mg} / \mathrm{kg}$ and established a median lethal dose of $800 \mathrm{mg} .{ }^{52}$ Infants and children are believed to be relatively more sensitive to opiates on a bodyweight basis. ${ }^{31}$ Elderly patients are also comparatively intolerant to opiates. ${ }^{31}$

It is also difficult to predict the total amount of codeine or promethazine consumed by addicts on a daily basis to produce euphoric effects. Mattoo et al noted that the average level of use by addicts in northern India was clearly much beyond the therapeutic daily dose of 15-30 mL (all 46 treatment-seeking patients consumed $60 \mathrm{~mL}$ or more per day, and in half of them the daily quantity ranged between 200 and $500 \mathrm{~mL}){ }^{3}$ The standard formulation per $5 \mathrm{~mL}$ contained $9-15 \mathrm{mg}$ of codeine and $3 \mathrm{mg}$ of promethazine. ${ }^{2}$ Erowid recommends a starting dose of 30-60 mg and states most people settle at the $250 \mathrm{mg}$ per day mark to experience the best euphoria with the least side effects. ${ }^{52}$

Serious overdose with codeine is characterized by respiratory depression (a decrease in respiratory rate and/or tidal volume, Cheyne-Stokes respiration, and cyanosis), extreme somnolence progressing to stupor or coma, skeletal muscle flaccidity, cold and clammy skin, and sometimes bradycardia and hypotension. The triad of coma, pinpoint pupils, and respiratory depression is strongly suggestive of opiate poisoning. In severe overdosage, particularly by the intravenous route, apnea, circulatory collapse, cardiac arrest, and death may occur. Seizure activity may be related to hypoxia. Promethazine may add to the depressant effects of codeine. ${ }^{31-33}$

Signs and symptoms of overdosage with promethazine $\mathrm{HCl}$ range from mild depression of the central nervous system and cardiovascular system to profound hypotension, respiratory depression, unconsciousness, and sudden death. The anti-cholinergic toxidrome with hyperthermia, flushing, tachycardia, altered mental status, agitated delirium, dry mucosa, mydriasis, urinary retention, and gastrointestinal dysmotility may be seen. Other reported reactions include hyper-reflexia, hypertonia, ataxia, athetosis, and extensor-plantar reflexes (Babinski reflex). ${ }^{32}$ Stimulation may be evident, especially in children and geriatric patients. Convulsions may rarely occur. A paradoxical-type reaction has been reported in children receiving single doses of $75-125 \mathrm{mg}$ orally, characterized by hyperexcitability and nightmares. ${ }^{32}$

CPHCS may interact with monoamine oxidase inhibitors causing increased extrapyramidal effects. An initial small test dose is advisable to allow observation of any excessive narcotic effects or monoamine oxidase inhibitor interaction. Promethazine may increase, prolong, or intensify the sedative action of other central nervous system depressants, such as alcohol, sedatives/hypnotics (including barbiturates), narcotics, narcotic analgesics, general anesthetics, tricyclic antidepressants, and tranquilizers; therefore, such agents should be avoided or administered in reduced dosage to patients receiving promethazine $\mathrm{HCl}$. Excessive amounts of promethazine $\mathrm{HCl}$ relative to a narcotic may lead to restlessness and motor hyperactivity in the patient with pain; these symptoms usually disappear with adequate control of the pain. Concomitant use of other agents with anticholinergic properties should also be undertaken with caution. ${ }^{32}$

\section{Management of cough in addicted patients}

A thorough review of the literature regarding OTC cough and cold medicines was carried out by Smith, Schroeder, and 
Fahey and published in the Cochrane Database of Systematic Reviews in 2012. In this review, the authors looked at 26 trials (18 in adults, 8 in children) involving more than 4,037 people. $^{53}$

In the adult studies, six trials compared antitussives with placebo and had variable results. Two trials compared the expectorant guaifenesin with placebo; one indicated significant benefit, whereas the other did not. One trial found that a mucolytic reduced cough frequency and symptom scores. Two studies examined antihistamine-decongestant combinations and found conflicting results. Three trials found antihistamines were no more effective than placebo in relieving cough symptoms. ${ }^{53}$

In the children studies, antitussives (two studies), antihistamines (two studies), antihistamine decongestants (two studies), and antitussive/bronchodilator combinations (one study) were no more effective than placebo. The results of one trial favored active treatment with mucolytics over placebo. ${ }^{53}$

The results of this review suggest that there is no good evidence for or against the effectiveness of OTC medications in acute cough. Many studies were of low quality and very different from each other, making evaluation of overall efficacy difficult. ${ }^{53}$

Expectorants increase bronchial mucus production, thus making coughs more productive. Guaifenesin, a ubiquitous expectorant found in OTC cough medicines, has minimally toxic effects limited to mild gastrointestinal irritation. ${ }^{22}$ It can be considered a safer alternative for use in patients with addiction to or dependence on other antitussives with high abuse potential.

Benzonatate (Tessalon Perles; Pfizer, New York, NY, USA) is a non-narcotic butylamine chemically related to ester anesthetics. It is thought to work by decreasing the sensitivity of stretch receptors in the lower airways and lung, making the cough reflex less active. Although benzonatate is a non-opioid and is not prone to abuse, it has a poor safety profile. There have been numerous reports of overdose resulting in neurotoxicity (seizures), cardiotoxicity (arrhythmias), and death, especially in children. ${ }^{54,55}$ A search of the United States Food and Drug Administration's Adverse Event Reporting System (AERS) database through May 19, 2010 identified 31 cases of overdose associated with benzonatate (median age 18 years, range 1-66 years). Common adverse events reported in the overdose cases included cardiac arrest, coma, and convulsion. Of the 31 overdose cases reported in AERS, seven cases involved accidental ingestions, all in children under the age of 10 years. Five of the seven accidental ingestions resulted in death in children aged 2 years and younger. ${ }^{56}$ Therefore, physicians should not routinely recommend benzonatate as an alternative antitussive, especially in children under the age of 10 .

\section{Patient and parental education}

Given the lack of data that antitussive medications are effective in children and their potential toxic effects, it would seem that they possess questionable utility in the setting of acute upper respiratory infection. Physicians should rather focus on parental education concerning the expected brief course of the cough and congestion and the importance of maintaining adequate hydration during these situations. Parents should also be reminded of the importance of safe storage of OTC cough medicines as well as other drugs found in the household in order to prevent unintentional ingestion. Parents and patients alike should be reminded of the dangers of opioid abuse and pharmaceutical misuse and dependence.

The American Academy of Pediatrics Committee on Drugs issued a policy statement in 1997 regarding the use of codeine-containing and dextromethorphan-containing cough remedies in children. ${ }^{57}$ The Committee concluded that the absence of well controlled studies failed to supported the use of codeine- and dextromethorphan-containing cough suppressants in children, since most coughs in children are viral in origin and resolve with fluids and supportive care. Moreover, the fact that dosage recommendations in children are extrapolated from adults increases the likelihood of preventable adverse events. ${ }^{57}$ For adults who are abusing or deemed dependent upon the euphoric effects of narcotic based cough and cold medicines, rehabilitation options for opioid addiction should be discussed and encouraged by providers.

\section{Conclusion}

Although abuse of dextromethorphan-containing cold and cough medicines is still prevalent, there has been a rise in the use of codeine-containing cough syrups, perhaps because of glorification of the effects by high profile figures in the mainstream media. Misuse and abuse of these products can be extraordinarily dangerous, resulting in serious neurotoxicity, cardiotoxicity, hepatotoxicity, and even death from respiratory failure. Health care professionals should be aware of the misuse and abuse potential of various antitussive medications. Efforts should be made to prescribe nonaddictive medications and to recommend alternative treatment options for cough and cold. Education of patients and parents to the dangers of these seemingly harmless OTC medications must be a top priority. 


\section{Disclosure}

The authors would like to share that there are no sources of funding support or conflicts of interest for this manuscript.

\section{References}

1. McCarthy M. Prescription drug abuse up sharply in the USA. Lancet. 2007;369:1505-1506.

2. Substance Abuse and Mental Health Services Administration. The NSDUH Report - Misuse of Over-the-Counter Cough and Cold Medications among Persons Aged 12 to 25. January 10, 2008. Rockville, MD: Substance Abuse and Mental Health Services Administration, Office of Applied Studies.

3. Mattoo SK, Basu D, Sharma A, Balaji M, Malhotra A. Abuse of codeine containing cough syrups: a report from India. Addiction. 1997;92(12): 1783-1787.

4. Wairadkar NS, Das J, Kumar S, et al. Codeine containing cough syrup addiction in Assam and Nagaland. Indian J Psychiat. 1994;36(3): 129-132.

5. Ishigooka J, Yoshida Y, Murasaki M. Abuse of "BRON": a Japanese OTC cough suppressant solution containing methylephedrine, codeine, caffeine and chlorpheniramine. Prog Neuropsychopharmacol Biol Psychiatry. 1991;15:513-521.

6. Lam CM, Shek DTL. A qualitative study of cough medicine abuse among Chinese young people in Hong Kong. J Subst Use. 2006;11(4): 233-244.

7. Wong KM, Chak WL, Cheung CY. Hypokalemic metabolic acidosis attributed to cough mixture abuse. Am J Kidney Dis. 2001;38(2): 390-394.

8. Boyer EW. Dextromethorphan Abuse. Pediatr Emerg Care. 2004;20(12):858-863.

9. Schwartz RH. Adolescent abuse of dextromethorphan. Clin Pediatr. 2005;44(7):565-568.

10. Bronstein AC, Spyker DA, Cantilena LR, Rumack BH, Dart RC. 2011 Annual Report of the American Association of Poison Control Centers National Poison Data System (NPDS): 29th Annual Report. London: Informa Healthcare; 2012. Available from: https://aapcc.s3.amazonaws. com/pdfs/annual_reports/2011_NPDS_Annual_Report.pdf. Accessed October 8, 2013.

11. Wilson MD, Ferguson RW, Mazer ME, Litovitz TL. Monitoring trends in dextromethorphan abuse using the National Poisoning Data System: 2000-2010. Clin Toxicol. 2011;49:409-415.

12. Peters R, Yacoubian GS, Rhodes W. Beliefs and social norms about codeine and promethazine hydrochloride cough syrup (CPHCS) use and addiction among multi-ethnic college students. J Psychoactive Drugs. 2007;39(3):277-282.

13. Agnich LE, Stogner JM, Miller BL, Marcum CD. Purple drank prevalence and characteristics of misusers of codeine cough syrup mixtures. Addict Behav. 2013;38:2445-2449.

14. Lewis R. Lil Wayne still hospitalized; Nicki Minaj, Drake among visitors. Los Angeles Times. March 18, 2013; Entertainment sect. Available from: http://articles.latimes.com/2013/mar/18/entertainment/ la-et-ms-lil-wayne-hospital-nicki-minaj-drake-20130318. Accessed June 19, 2013.

15. Hall M. The Slow Life and Fast Death of DJ Screw. Texas Monthly. Apr 2001. Available from: http://www.texasmonthly.com/story/slowlife-and-fast-death-dj-screw. Accessed August 25, 2013.

16. Hou H, Yin S, Jai S, et al. Decreased striatal dopamine transporters in codeine-containing cough syrup abusers. Drug Alcohol Depend. 2011;118:148-151.

17. Bronstein AC, Spyker DA, Cantilena LR, Rumack BH, Dart RC. 2011 Annual Report by the American Association of Poison Control Centers' National Poison Data System (NPDS): 29th Annual Report. Clin Toxicol. 2012;50:911-1164.
18. Hutchings HA, Eccles R. The opioid agonist codeine and antagonist naltrexone do not affect voluntary suppression of capsaicin induced cough in healthy subjects. Eur Respir J. 1994;7:715-719.

19. Nelson LS. Opioids. In: Flomenbaum NE, Goldfrank LR, Hoffman RS, et al. editors. Goldfrank's Toxicologic Emergencies. 8th ed. New York: McGraw-Hill; 2006:590-613.

20. Kamei J. Delta-opioid receptor antagonists as a new concept for central acting antitussive drugs. Pulm Pharmacol Ther. 2002;15: 235-240.

21. Reynolds SM, Mackenzie AJ, Spina D, Page CP. The pharmacology of cough. Trends Pharmacol Sci. 2004;25:569-576.

22. Carr BC. Efficacy, abuse, and toxicity of over-the-counter cough and cold medicines in the pediatric population. Curr Opin Pediatr. 2006;18: 184-188.

23. Barnhart J, Massad E. Determination of dextromethorphan in serum by gas chromatography. J Chromatogr. 1979;163:390-395.

24. Silvasti M, Karttunen P, Tukiannen H. Pharmacokinetics of dextromethorphan and dextrorphan: a single dose comparison of three preparations in human volunteers. Int J Clin Pharmacol Ther. 1987;9:493-497.

25. Baselt R, Cravey R. Disposition of Toxic Drugs and Chemicals in Man. Chicago: Yearbook Medical Publishers; 1989.

26. Schadel M, Wu D, Otton S, et al. Pharmacokinetics of dextromethorphan and metabolites in humans: influence of the CYP2D6 phenotype and quinidine inhibition. J Clin Psychopharmacol. 1995;15:263-269.

27. Steinmiller C, Maisonneuve I, Glick S. Effects of dextromethorphan on dopamine release in the nucleus accumbens. Pharmacol Biochem Behav. 2003;74:803-810.

28. Graudins A, Ferm R. Acute dystonia in a child associated with therapeutic ingestion of a dextromethorphan-containing cough and cold syrup. J Toxicol Clin Toxicol. 1996;34:351-352.

29. Kim H, Park I, Park W. NDMA receptor antagonists enhance 5-HT2mediated behavior. Arch Pharmacol Res. 1999;22:113-118.

30. American Society of Health-System Pharmacists. Codeine. In: McEvoy GK, editor. AHFS Drug Information. Bethesda, MD: American Society of Health-System Pharmacists; 2003:2570-2572.

31. Drugs.com [homepage on the Internet]. Codeine. Available from: http:// www.drugs.com/codeine.html. Accessed June 19, 2013.

32. Drugs.com [homepage on the Internet]. Promethazine with codeine. Available from: http://www.drugs.com $/ \mathrm{mtm} /$ promethazine-withcodeine.html. Accessed June 19, 2013.

33. RxList [homepage on the Internet]. Codeine sulfate. Available from: http://www.rxlist.com/codeine-sulfate-drug/clinical-pharmacology.htm. Accessed June 19, 2013.

34. Strenkoski-Nix LC, Ermer J, DeCleene S, Cevallos W, Mayer PR. Pharmacokinetics of promethazine hydrochloride after administration of rectal suppositories and oral syrup to healthy subjects. Am J Health Syst Pharm. 2000;57(16):1499-1505.

35. Taylor G, Houston JB, Shaffer J, Mawer G. Pharmacokinetics of promethazine and its sulphoxide metabolite after intravenous and oral administration. Br J Clin Pharmac. 1983;15:287-293.

36. Kathiramalainathan $\mathrm{K}$, Kaplan H, Romach MK, et al. Inhibition of cytochrome P450 2D6 modifies codeine abuse liability. J Clin Psychopharm. 2000;20(4):435-444.

37. White W. DXM FAQ, 1995. Available at: http://www.erowid.org/ chemicals/dxm/faq/. Accessed June 19, 2013.

38. Boyer EW. Dextromethorphan Abuse. Pediatr Emerg Care. 2004;20(12):858-863.

39. Banerji S, Anderson I. Abuse of Coricidin HBP cough and cold tablets: episodes recorded by a poison center. Am J Health Syst Pharm. 2001;58:1811-1814.

40. Kirages T, Sule H, Mycyk M. Severe manifestations of coricidin intoxication. Am J Emerg Med. 2003;21:648-651.

41. Hinsberger A, Sharma V. Cognitive deterioration from long-term abuse of dextromethorphan: a case report. J Psychiatry Neurosci. 1994;19: 375-377.

42. Fleming P. Dependence on dextromethorphan hydrobromide. $\mathrm{Br} \mathrm{Med}$ $J$ (Clin Res Ed). 1986;293:597. 
43. Wolfe T, Caravati E. Massive dextromethorphan ingestion and abuse. Am J Emerg Med. 1995;13:174-176.

44. Nicholson K, Hayes B, Balster R. Evaluation of the reinforcing properties and phencyclidine-like discriminative stimulus effects of dextromethorphan and dextrorphan in rates and rhesus monkeys. Psychopharmacology. 1999;146:49-59.

45. Dodds A. Toxic psychosis due to dextromethorphan. Med J Aust. 1967;2:231

46. Schadel M, Sellers E. Psychosis with Vicks Formula 44-D abuse. Can Med Assoc J. 1992;147:843-844.

47. Helfer J, Kim O. Psychoactive abuse potential of Robitussin-DM. Am J Psychiatry. 1990;147:672-673.

48. Ng Y, Lin W, Chen T, et al. Spurious hyperchloremia and decreased anion gap in a patient with dextromethorphan bromide. Am J Nephrol. 1992;12:268-270.

49. Galanter M, Kleber HD. The American Psychiatric Publishing Textbook of Substance Abuse Treatment. 4th ed. United States of America: American Psychiatric Publishing Inc; 2008:217.

50. Bowdle T. Adverse effects of opioid agonists and agonist-antagonists in anaesthesia. Drug Saf. 1998;19:173-189.

51. Shannon M. Methylenedioxymethamphetamine. Pediatr Emerg Care. $2000 ; 16: 377-380$
52. MDH, Jbuzdyga. Codeine FAQ. 1996. Available from: http://www.erowid. org/pharms/codeine/codeine_faq.shtml. Accessed June 19, 2013.

53. Smith SM, Schroeder K, Fahey T. Over-the-counter (OTC) medications for acute cough in children and adults in ambulatory settings. Cochrane Database Syst Rev. 2012;8:CD001831.

54. Crouch BI, Knick KA, Crouch DJ, Matsumura KS, Rollins DE. Benzonatate overdose associated with seizures and arrhythmias. JToxicol Clin Toxicol. 1998;36(7):713-718.

55. Cohan JA, Manning TJ, Lukash L, Long C, Ziminski KR, Conradi SE. Two fatalities resulting from Tessalon (benzonatate). Vet Hum Toxicol. 1986;28(6):543-544.

56. US Food and Drug Administration. FDA Drug Safety Communication: Death Resulting from Overdose after Accidental Ingestion of Tessalon (Benzonatate) by Children under 10 years of Age. December 14, 2010. Rockville, MD. Available from: http://www.fda.gov/Drugs/DrugSafety/ ucm236651.htm. Accessed June 20, 2013.

57. American Academy of Pediatrics Policy Statement. Use of codeine- and dextromethorphan-containing cough remedies in children. Pediatrics. 1997;99:918-920.
Substance Abuse and Rehabilitation

\section{Publish your work in this journal}

Substance Abuse and Rehabilitation is an international, peer-reviewed, open access journal publishing original research, case reports, editorials, reviews and commentaries on all areas of addiction and substance abuse and options for treatment and rehabilitation. The manuscript management system is completely online and includes a very quick and fair

\section{Dovepress}

peer-review system. Visit http://www.dovepress.com/testimonials.php to read real quotes from published authors. 